\title{
Nithikul Nimkulrat Situating Creative Artifacts in Art and Design Research
}

\begin{abstract}
This article aims to discuss the position of art and design artifacts, and their creation, in a practice-led research process. Two creative productions and exhibitions featuring my textile artifacts were intentionally carried out in order to tackle a specific research problem, and these will be examined here as case studies. These cases cover the production and exhibition of two sets of artworks, named Seeing Paper and Paper World, that were created as part of my completed doctoral research entitled Paperness: Expressive Material in Textile Art from an Artist's Viewpoint. The study examined the relationship between a physical material and artistic expression in textile art and design. Both cases exemplify the roles of creative productions and artifacts situated in the process of inquiry. Throughout a practice-led research process, art and design artifacts can serve as inputs into knowledge production and as outputs for knowledge communication. As inputs, both art productions and artifacts can be the starting point of a research project from which the research question is formulated. They can also provide data for analysis from which knowledge is constructed. As outputs, artifacts can indicate whether the research problem requires reformulation, demonstrate the experiential knowledge of the creative process, and strengthen the findings articulated in the written output. Creative practice in a research context can contribute to generating or enhancing the knowledge which is embedded in the practice and embodied by the practitioner. This knowledge or insight can be obtained from the artist creating the artifact, the artifact created, the process of making it, and the culture in which it is produced and viewed or used, all taking place at different stages of a research process.
\end{abstract}

Keywords: practice-led, artifacts, art, craft, design, experiential knowledge

\section{Introduction: creative practice and practice-led research}

Research is often understood by artists and designers as a requisite component of their professional creative practice, especially when they delve into topics beyond their own professions and personalities through visual methods such as drawing and painting (Scrivener, 2009). Research in this sense can be categorized as research for art (Frayling, 1993), which is not considered academic research but rather a means to explore ideas and gather information in an artistic process (Nimkulrat, 2009, pp. 33-34). According to Scrivener (2009), this is considered research with a small " $r$ " and it generally exists in an artist's or a designer's creative process. Nevertheless, research in professional art and design practice can extend its territory into the academic context and function as part of a case study to be scrutinized and reflected on in a piece of scholarly research. Conversely, artistic processes and artifacts created as vehicles for research can be recognized as "art proper" in the artworld when they can also reach a non-academic audience (Figure 1). The contextual shift of research for general creative practice in one direction and creative practice in academia in the opposite, creates a partial crossover between academia and the artworld. Similarly, Biggs and Karlsson (2011) examine the degree of overlap in the aims and objectives of academic research and professional arts practice and suggest a model of hybridization towards the creation of an "arts research paradigm" (pp. 409-410) (Figure 2). These models show a shared understanding of practice-based or practice-led research that has been developed in parallel to the field of art and design. 


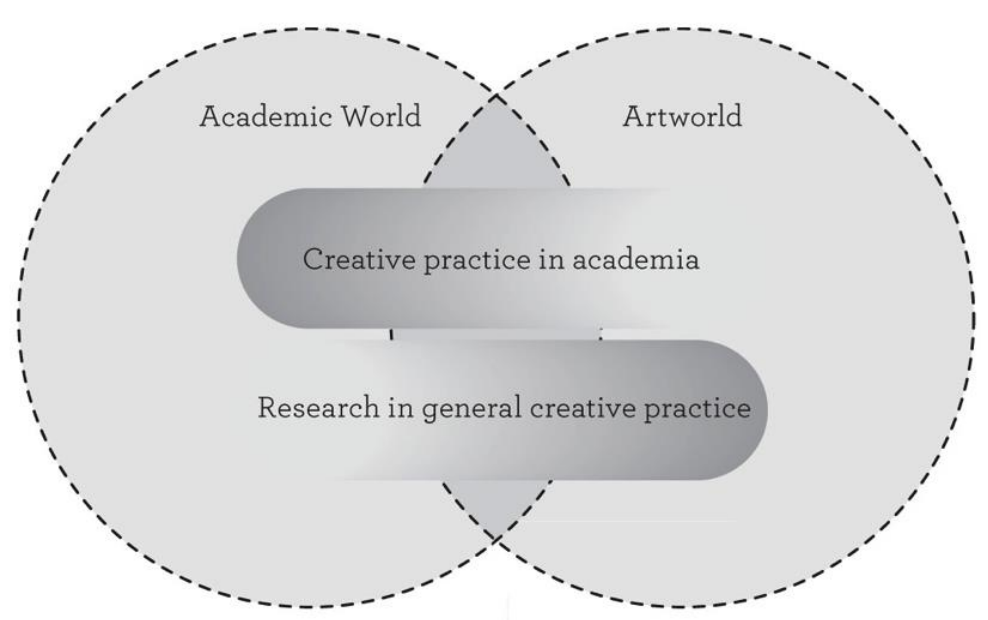

Figure 1: Model illustrating the place for research in general creative practice in academia, and the place for creative practice in academia in the artworld (Nimkulrat, 2009, p. 34).

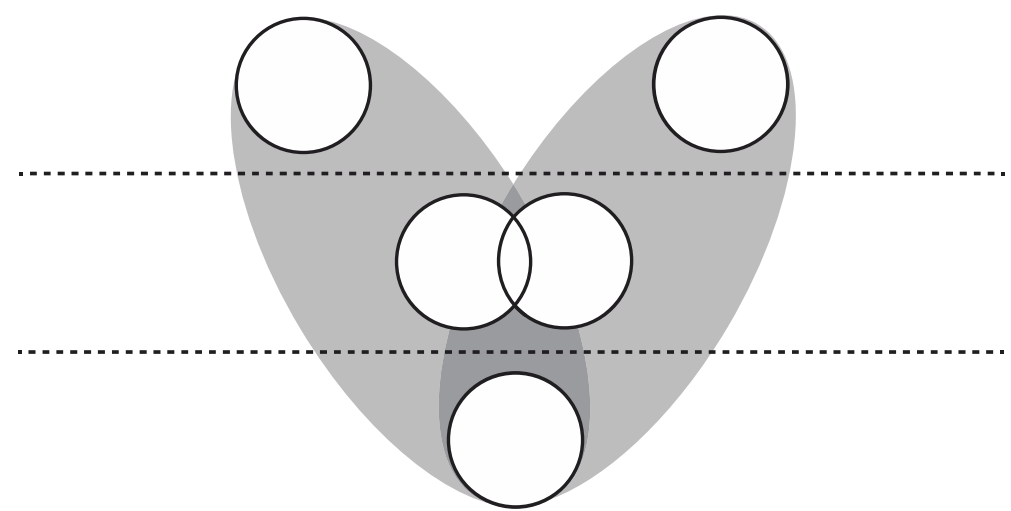

Figure 2: Model of three different degrees of overlap between arts practice and academic research (Biggs \& Karlsson, 2011, p. 409).

Having been immersed in art and design academia for nearly three decades, this practice-led research approach considers the researcher's creative practice (i.e., the making of material artifacts) as the main vehicle for study, the results of which include not only written text but also artifacts to be evaluated in a research context. Creative practice is intentionally utilized in this research as a questioning process constructed to collect data and to generate reflection about the practice (Durling, 2002). Durling also stresses that although practice and research coexist and interact each other, they are distinct categories and should not be misunderstood as identical. Likewise, Friedman (2003) points out that an understanding that "practice is research" and "practice-based research is ... a form of theory construction" is mistaken (p. 519). Theory can be developed from practice through articulation and inductive inquiry. Without articulation and inductive inquiry, practice as such cannot be developed into theory. The understanding of "practice as research" contributes to a problematic assumption that the outcomes of creative practice, i.e., artifacts, can be considered the outcomes of research without the inclusion of a substantial written outcome (Nimkulrat, 2011, p. 60). Biggs (2004) maintains that if non-linguistic research outcomes alone were acceptable in art and design, the discipline would no longer be comparable to other disciplines, and therefore such outcomes should not be positioned in an academic context at all. While an artifact created with a research intention can contribute to communicating the tacit content of research nonlinguistically, experiential feeling in creative practice has a representational connection to experiential content that can be represented linguistically (Biggs, 2004). Accordingly, the results of practice-led research are expected to include not only a written text but also artifacts 
to be evaluated in a research context. The knowledge contribution that is a core requirement of academic research should also be explicit enough in the artifact produced (Lycouris, 2011). An array of terminology, including "practice-led," "practice-based," "process-led," "studiobased," "arts-based," "practice as research," "research by design," and "artistic research," has been used to refer to this form of academic research (Biggs, 2006, p. 185). Although these various terms may reflect the different roles of creative practice in academic research (Niedderer \& Roworth-Stokes, 2007), their meanings and usages vary among countries, institutions, subject areas, and even scholars within a higher education institution. For example, "practice-led research" is the current term used in most universities in the UK and in the design discipline, whereas "artistic research" is used more extensively in other European countries and in the field of fine arts (Nimkulrat, 2011, p. 60).

This article aims to discuss the position of art and design artifacts, and their creation, in a practice-led research process. Two creative productions and exhibitions featuring my textile artifacts, that were carried out in order to tackle specific research questions, are examined as case studies. The cases comprise the production of two series of textile artworks and two exhibitions, namely Seeing Paper and Paper World, created as part of my completed doctoral research (Nimkulrat, 2009). The research examined the relationship between a physical material and artistic expression in contemporary textile art and design.

The term "practice-led" will be adopted in this article because it highlights the active role of creative practice in the research process (Nimkulrat, 2009, p. 37), and most clearly explains my study in which professional artistic practice leads the process of inquiry to generate a new or enhanced understanding of the expressive potential of material in textile art and design.

\section{Creative productions and artefacts in the process of inquiry}

The thesis entitled Paperness: Expressive Material in Textile Art from an Artist's Viewpoint (Nimkulrat, 2009) researched at the University of Art and Design, Helsinki in Finland (currently Aalto University School of Arts, Design and Architecture) examined the relationship between a physical material and artistic expression in textile art and design. Material and skills are the most important elements in any creation within textiles and other craft-based disciplines such as glass, ceramics, jewelry, etc. They could be considered characteristics of material-based or craft-based fields that is rather distinguishable from fine arts (Nimkulrat, 2012). The material chosen for this investigation was paper string. The possible incorporation of two concepts-paper string and artistic expression-was the problem field of the study (Figure 3).

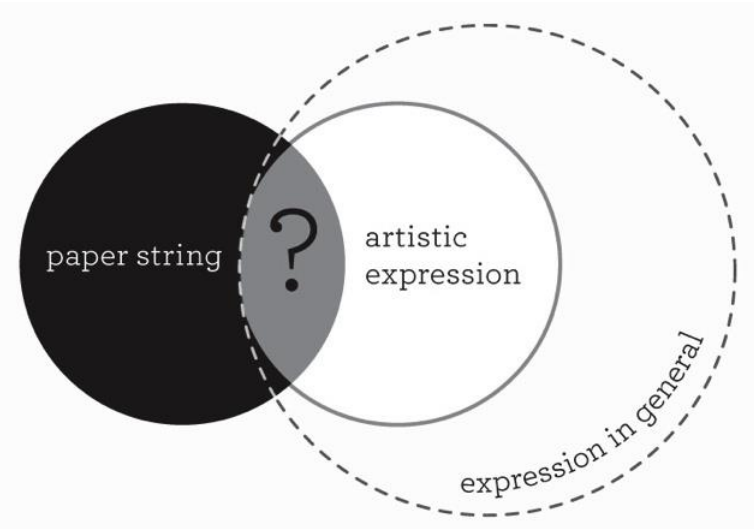

Figure 3: Model of the research problem field: the relationship between paper string and artistic expression (Nimkulrat, 2009, p. 24). 
While the existence of paper string is evident through physical contact, artistic expression seems to take place during a creative process when a textile practitioner is working with a material. To problematize the research problem field further, this study set out to investigate paper string's influence on a textile artist working with the material in actual artistic practice. The focus on the influence of paper string on the creative process led to the following research questions:

1) How does paper string, when used to create artistic textiles, influence a textile practitioner, her artistic process, and the resulting artifact?

2) How does artistic expression arise in a creative process through the use of paper string as the chosen material?

3) What could be considered the expressive qualities of paper string?

The above research questions implied the importance of the experience of a textile practitioner working with paper string in specific artistic processes, as well as a reflection on the practitioner's own experience in actual practice. One possible way to observe and reflect on actual textile practice was to adopt the role of a practitioner. In textile practitioners' everyday lives, they learn by doing things rather than by considering the theory/theories underlying them. According to Jarvis (2012), practice may precede theory. Practitioner research is pragmatic and based upon the understanding of learning about phenomena taking place or being experienced through practice, so that theory itself can follow the experiential learning (Jarvis, 1999). Hence, the research questions of this study were approached through the making of textile artifacts, and then examining my own practice and discussing my experience with the paper string used in the art productions. It is worth mentioning here that before I began my $\mathrm{PhD}$, I had not used paper string in my textile practice. The aim of having no prior experience with the material was to make me more aware of my own creative process, so that I would be able to generate reflection more efficiently. As Jarvis (1999) points out, reflective practice takes place where practitioner-researchers "are problematizing their practice and learning afresh about both the knowledge and skills and attitudes that their practice demands" (p. 178).

The thesis was practice-led and regarded the artistic productions and resulting artifacts as case studies. With this approach, I could scrutinize my own creative processes by crafting artworks as an artist, and by documenting, reflecting on, and analyzing the processes used in relation to relevant scholarly literature as a researcher. By means of documentation, the creation of artifacts that attempt to solve the research problem can give rise to a connection between academia and the artworld (Figure 4).

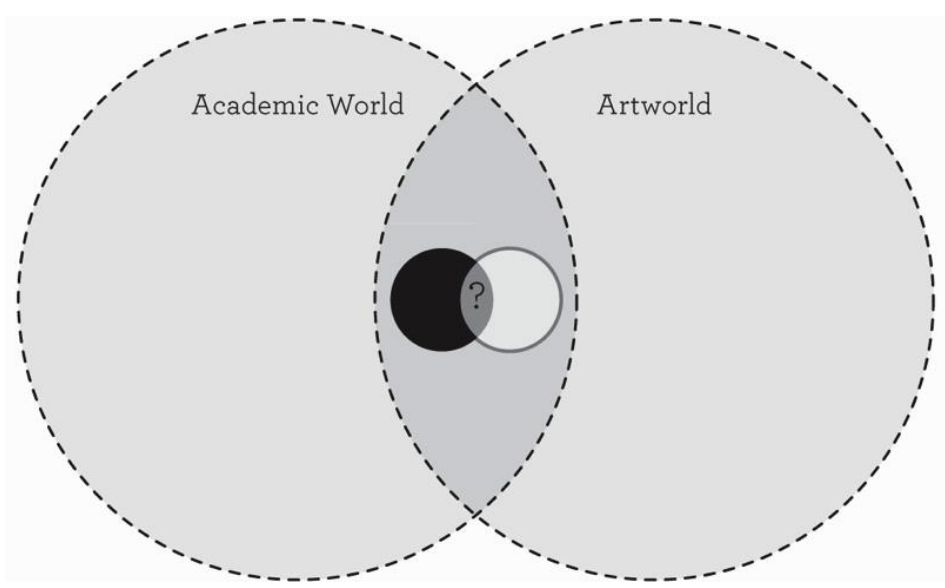

Figure 4: Location of this research in the academic world and the artworld (Nimkulrat, 2009, p. 26). 
In this article, the study is used to exemplify the roles of creative productions and artifacts when situated in the process of inquiry, which was constructed around two art productionsSeeing Paper and Paper World. These were separated into five phases: 1) Before the actual creation of the artwork, 2) The actual creation of Seeing Paper, 3) After the actual creation of Seeing Paper, 4) The actual creation of Paper World, and 5) After the actual creation of Paper World (Figure 5). This practice-led research process began with the problem preliminarily posed, i.e., the relationship between a physical material (paper string) and artistic expression in the creation of art textiles. The two components, a physical material (paper string) and artistic expression, stayed the focus throughout the whole research process.

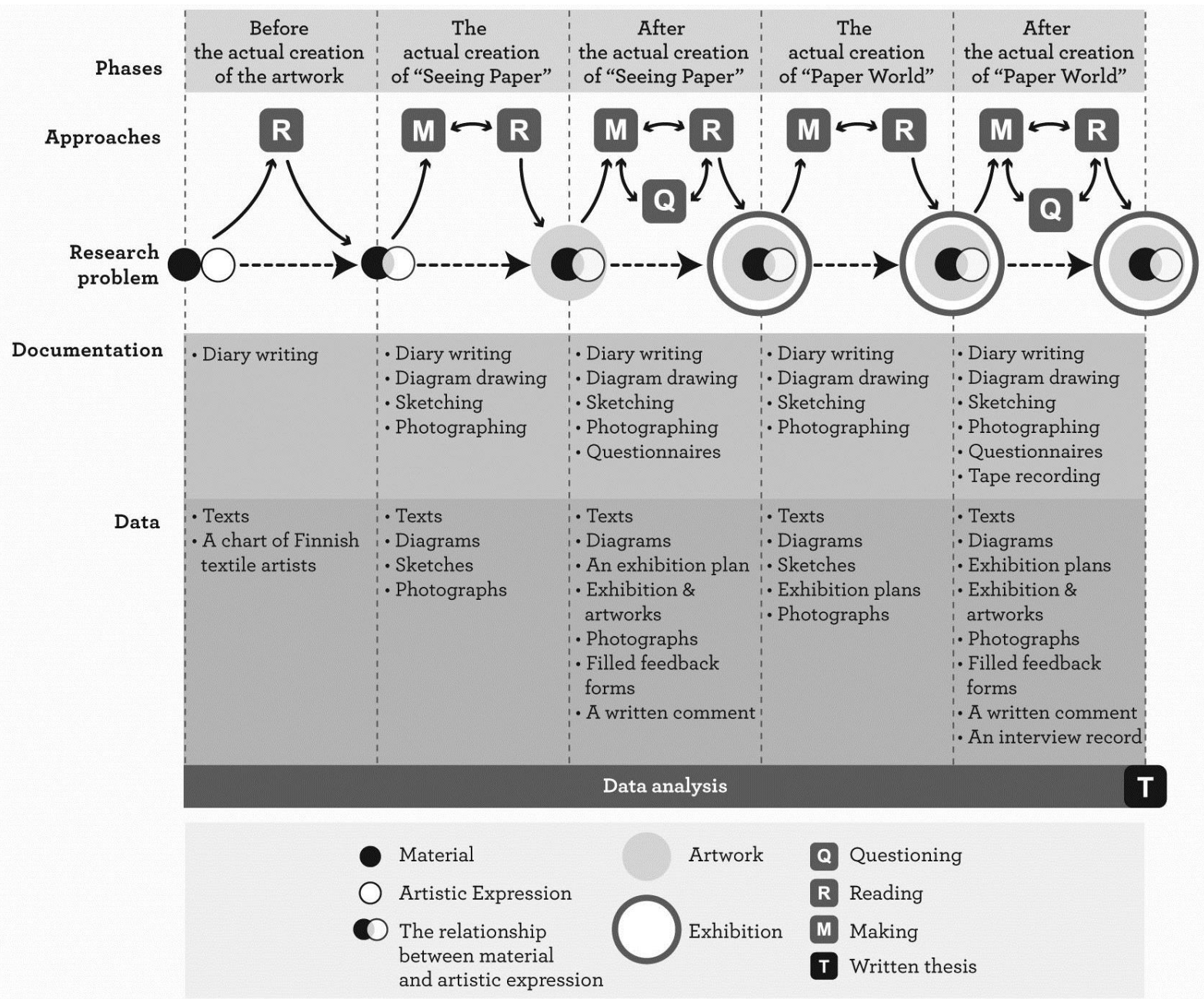

Figure 5: Process of inquiry divided into five phases (Nimkulrat, 2009, p. 57).

As can be seen in Figure 5, the research problem was framed first as two elements: physical material and artistic expression. To study the importance of a material, as to whether it helps a textile artist construct artistic expression, the two elements must interact with each other and a type of material must be specified. Examining every type of textile material was certainly inappropriate, as the subject of the study would be too broad. This was the stage when research into general creative practice took place within an academic research process, in order to select a material to be used in creative practice to perform as the vehicle for theoretical inquiry. A literature survey about the history of textile art in Finland (e.g., Kruskopf, 1975; Svinhufvud, 1998), and the location of this academic research and creative practice, was conducted. From the survey, paper string and its conflicting characteristics 
interested me most. On the one hand, the material seems ordinary-it is industrially produced in the form of yarns, just like other textile materials. On the other hand, it is rather special because it is produced from wood, unlike many other textile materials. Not having used this material before, the challenge of using a new medium would enhance my awareness and my articulation of the creative process.

Paper string and artistic expression were then explored separately. Studying each of them as an individual element allowed me to become familiar with them and be able to generate ideas regarding how they could be incorporated into my actual practice. The conceptual interweaving of the two elements equipped me for the second phase of research that involved the actual creation of Seeing Paper and the intertwining of material and expression.

\section{Case 1: Seeing Paper}

To create Seeing Paper in the second phase, three different kinds of paper string were used as the material (Figure 6). This art production was conceptualized by the use of metaphor as "imaginative rationality" to blend reason and imagination (Lakoff \& Johnson, 1980, p. 194). According to Lakoff and Johnson a metaphor, as discussed from the experientialist perspective, permits imagination to possess rationality, so that one kind of experience can be understood in terms of another. A metaphor is "capable of giving us a new understanding of our experience" (p. 140) and is "one of our most important tools for trying to comprehend partially what cannot be comprehended totally: our feelings, aesthetic experiences, moral practices, and spiritual awareness" (p. 194). Centering upon the use of metaphor and the argument that a material has specific expressive potential, the concept of Seeing Paper aimed to illustrate that a material metaphorically lives in this world. A material in this metaphorical sense is not passive, but active and interactive with the artist. This concept was developed into the idea of creating artworks in a form of dress-like sculptures, as a metaphor for female human beings.
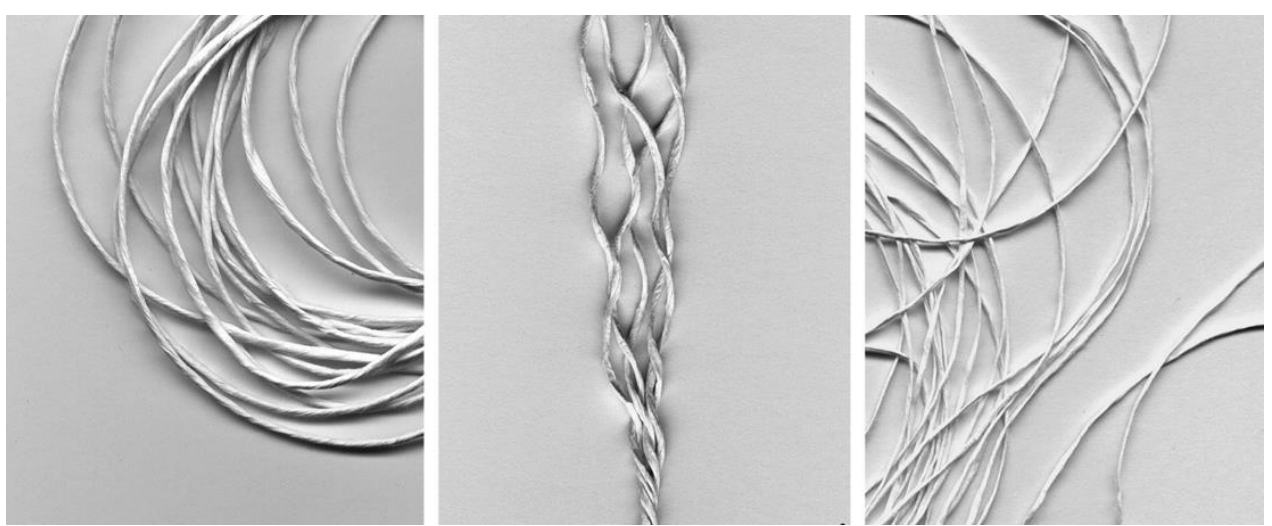

Figure 6: The three different types of paper string used in the creation of Seeing Paper (Nimkulrat, 2009, p. 110).

The manipulation of each type of paper string by hand initiated a distinctive dialogue between the material and the maker's expression. When expressing an idea through the hand manipulating the material into a tangible form, I felt that the material reacted to my manipulative act. This indicated that the visual and tactile qualities of each material I touched in the creative process influenced my thoughts and imagination and resonated with some of my past experiences. I then manipulated the material in response to these influences and resonances. A tactile phenomenon such as this can be associated with human perception or consciousness, as Merleau-Ponty (1962) states: 
I am able to touch effectively only if the phenomenon finds an echo within me, if it accords with a certain nature of my consciousness, and if the organ which goes out to meet it is synchronised $[\mathrm{sic}]$ with it. The unity and identity of the tactile phenomenon do not come about through any synthesis of recognition in the concept, they are founded upon the unity and identity of the body as synergic totality (p. 369).

The three types of paper string used to create this series of artworks performed differently, and by the end of the second phase of research, gave rise to unwearable dresses representing women of different characteristics (Figure 7). "Reflection-in-action," to use Schön's term (1983; 1987), took place via daily chronicling about each work in progress in my research diary, through writing and drawing diagrams, as well as photographing the work in different states. Reflection-in-action contemplates the consequences of action whilst the practitioner is in the process, i.e., the reflection occurs within the action itself (Schön, 1983, pp. 62-68). After adopting this research, the practice of reflection-in-action enabled the practitionerresearcher to critically examine her own creative process and contributed to the transparency of research led by art practice.

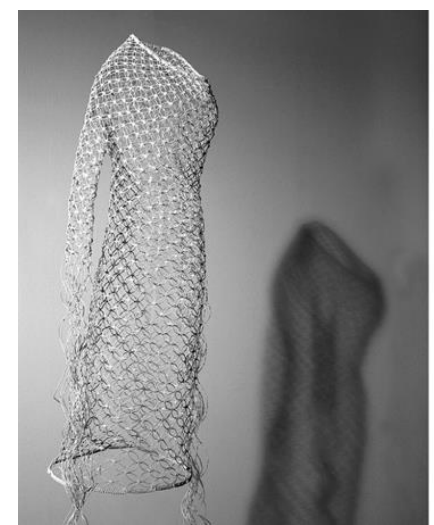

a

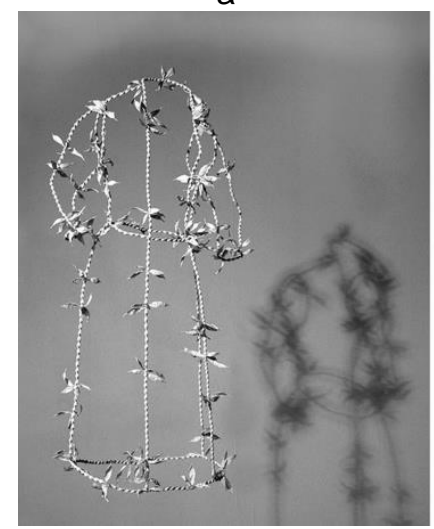

d

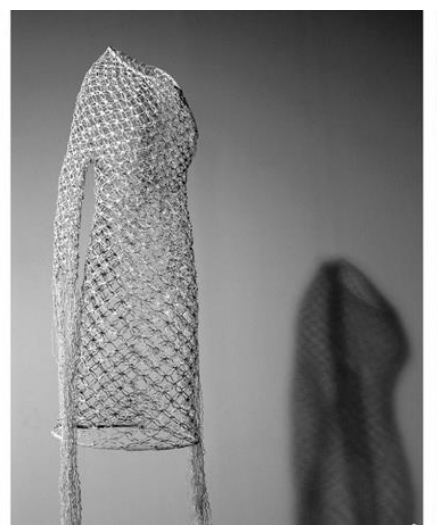

b

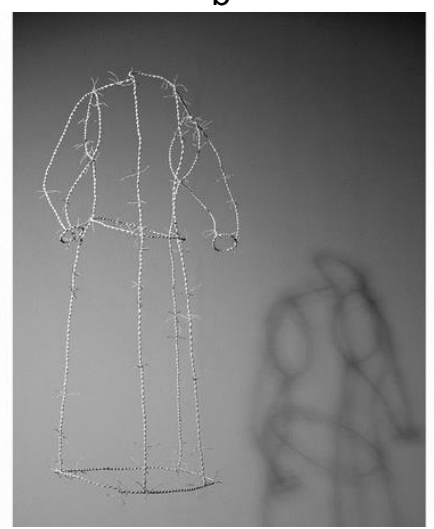

e

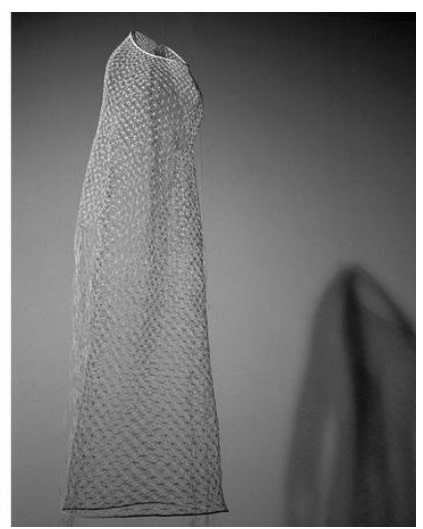

C

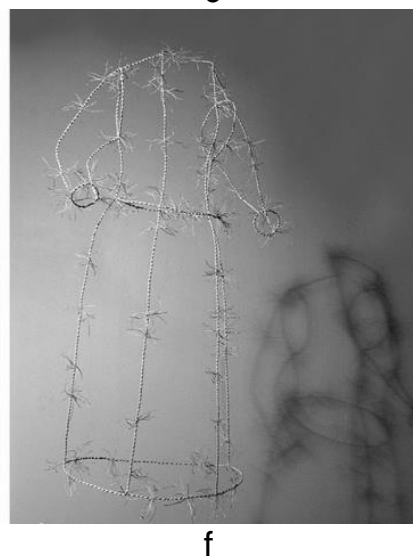

Figure 7: Six dress-like sculptures in the Seeing Paper series: (a) Let Go, (b) Get Sorted, (c) Breathe Easily, (d) Private Garden, (e) Private Area, and (f) Personal Joy (Nimkulrat, 2009, pp. 123, 127). Let Go and Private Garden are made of the same type of paper string, so are Get Sorted and Private Area as well as Breathe Easily and Personal Joy.

The artistic output (i.e., the Seeing Paper series of artworks) produced in the second phase became the research problem in the third phase, when it was publicly displayed in an exhibition (Figure 8). In the exhibition, questioning was utilized as a research approach in the form of printed questionnaires for visitors to fill in (Figure 9). The questionnaire, a simple form of qualitative research, was intended to guide the visitors to interpret and remark upon 
each individual artwork. The visitors' answers were informative, providing the artist with evidence of how the artworks and the exhibition were, and could be, interpreted. Although these answers were included in the data collection, they were not validated as sociological data. In this study, the visitors' responses acted as data that the artist-researcher took further for the development of her subsequent creative work performed as part of the research. The development of artistic practice then led to the reformulation of the research problem field set in the beginning of the research project.

In the Seeing Paper case, the viewers' written feedback revealed that they could not recognize any differences in the expressive qualities of the three types of paper string, nor could they interpret the female dress-like sculptures as a metaphor. The unrecognizable concept and variations of the materials in the artworks indicated the influence of the exhibition space on the exhibits for consideration. The concept of "the white cube" (O'Doherty, 1999) shows that the white space of a modernistic gallery creates the feeling of timelessness in visitors and, hence, is not as neutral as it appears to be. This directed me to reflect on the art production and exhibition to reformulate the research problem to incorporate contextual elements into the study, and to adjust the way of creating the next art production. According to Schön (1987), "Reflection-on-action" is retrospective learning taking place after the action itself, which involves thinking about previous experiences, analyzing them, and then developing personal theories of action - the result of which is the change of future actions (pp. 26-31). In the Seeing Paper case, the changes made in the subsequent art production (i.e., Paper World) and those made to the research problem, lay in the inclusion of the exhibition context into the creative and research processes. Hence, all artworks in Seeing Paper can be considered inputs into the production of knowledge for the third phase of research. Without them, I would not have understood my audience nor reflected upon their interpretation and consequently re-shaped my creative process and developed the research problem in an altered direction.

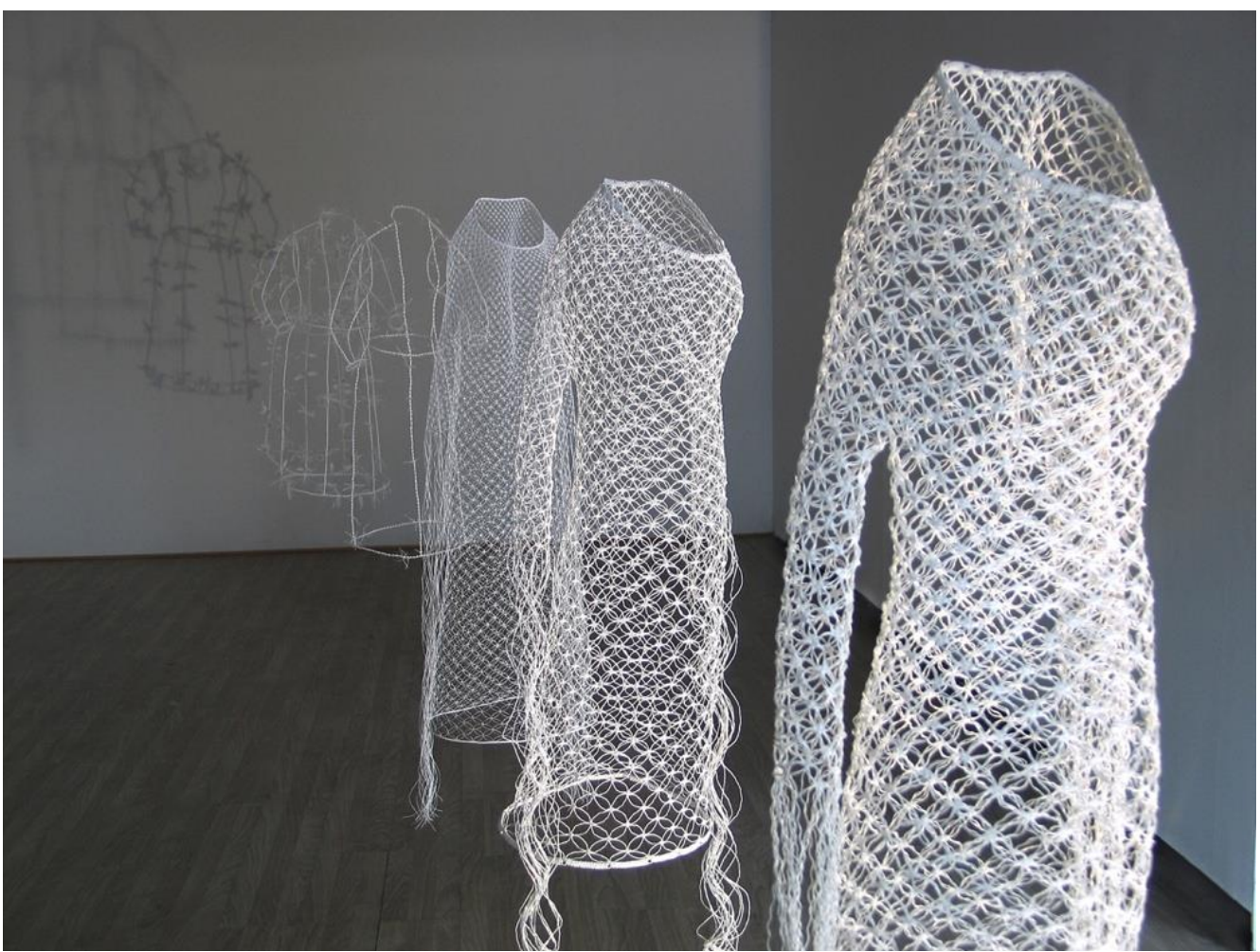

Figure 8: Seeing Paper displayed in a modernist gallery (Nimkulrat, 2009, p. 158). 


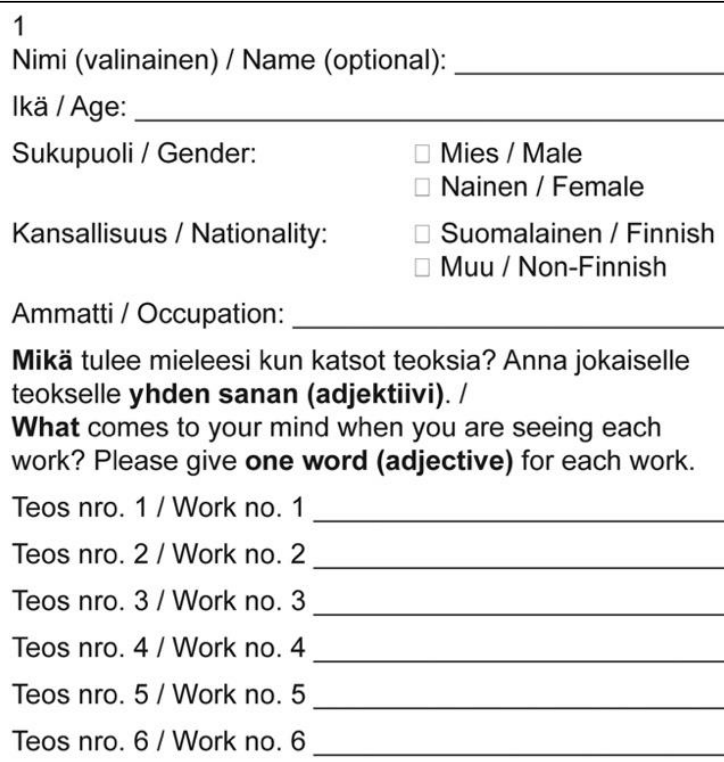

Figure 9: Questionnaire for Seeing Paper (Nimkulrat, 2009, p. 67).

\section{Case 2: Paper World}

In the fourth phase, the relationship between paper string and artistic expression was explored in connection with the exhibition context. The creation of Paper World as a vehicle for research in this phase was reframed to emphasize not only the material that constructed each artwork, but also the overall exhibition in which all artworks were to be situated, in order to gain knowledge about the relationship between the material and artistic expression (Figure 10).
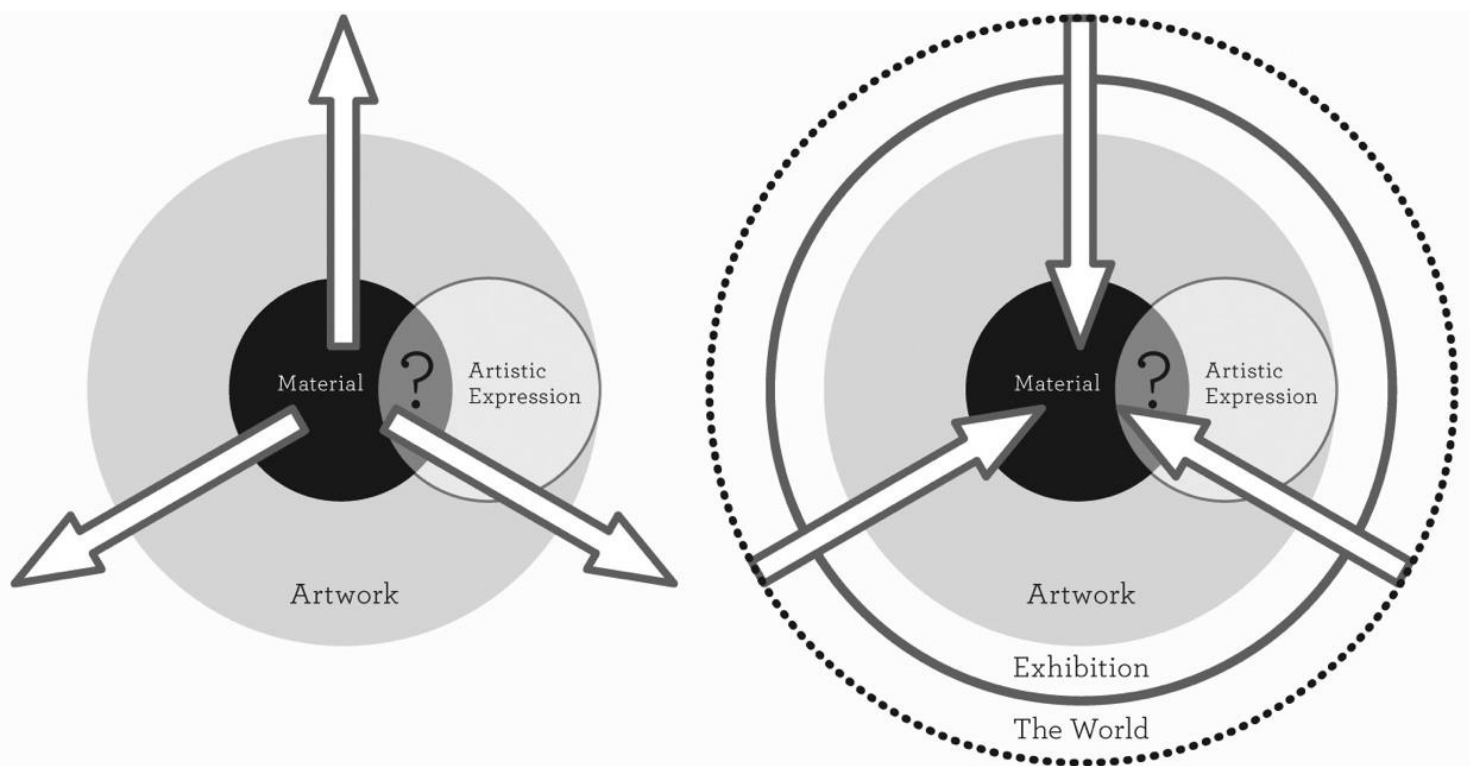

Figure 10: The creative process of Paper World (right) in comparison with that of Seeing Paper (left) (Nimkulrat, 2009, p. 129).

I had an increased awareness of the visitors' perceptions that connected their contemplation of the artworks with their surroundings and with their personal experiences. The questioning approach in the previous phase of research was able to shed light on how I could predict and direct the reception of Paper World. While conceptualizing this second art production, I anticipated how the visitors might experience the exhibition in order to determine the art 
series' concept that would lead most people to experience the artworks as I intended. Based on Dewey's Art as Experience concept (1934), when the artist adopts the position of a viewer while creating artworks, the viewers in response attempt to learn the artist's standpoint to understand what the artworks try to convey (pp. 48-56). According to Heidegger's phenomenological thinking (1999), one interprets the meaning of a thing as it is "in the world," not by looking at it as a general thing, but by referring it to his or her own contextual correlation (pp. 65-70). Merleau-Ponty (1962) states that one experiences an object from an embodied standpoint within a spatial temporal context (pp. 77-83). To perceive an object is to be in the same world as the object experienced. Its coexisting objects are also perceived in an act of seeing, all reflecting one another. These phenomenological concepts informed the creation of Paper World, helping me to conceptualize its theme. In order to shape the visitors' experience and interpretation of my artworks in the direction I anticipated, their forms and the space in which they were presented should be recognizable by the audience, and should have a comparable meaning for them and for me. Accordingly, the concept of Paper World was to show that a material lives in this world, as do everyday objects surrounding us in our daily lives at home. Thus, a gallery converted from a residential home was selected as the context for the exhibition (Figure 11).

Directing the reception of artifacts may not usually be desired in art, but it is rather desirable in design. Textile art in Finland belongs to the design domain of the Finnish tradition; I therefore valued the audience's perception and interpretation of my work. In the Paper World case, even if my artworks were expected to have a meaning relevant to the material used, their meaning tended to be open to interpretation, i.e., people seemed to have different opinions about the artwork. As interpretation introduces the meaning of something understood by an individual, meaning cannot occur as one single truth. This suggests that a tangible thing can hold multiple meanings depending on who produces the interpretation, and that this understanding is based on the previous experiences a person has had as well as where and when the interpretation takes place.

"Reflection-in-action" (Schön, 1983; 1987) in visual and textual formats also played its role throughout this phase of research-I kept various forms of documentation, e.g., photographing and writing about each work in progress. These records detailed practical knowledge that is usually implicit in creative practice.

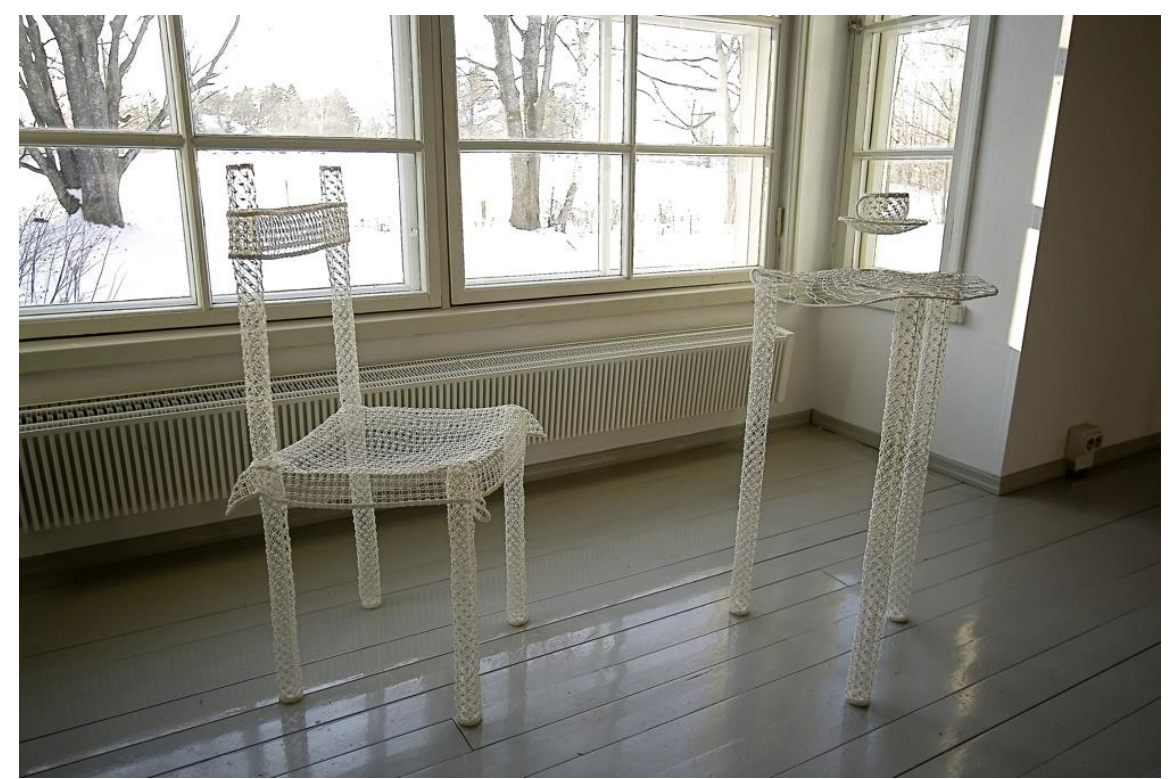

Figure 11: Paper World displayed in a gallery converted from a residential home (Nimkulrat, 2009, p. 225). 


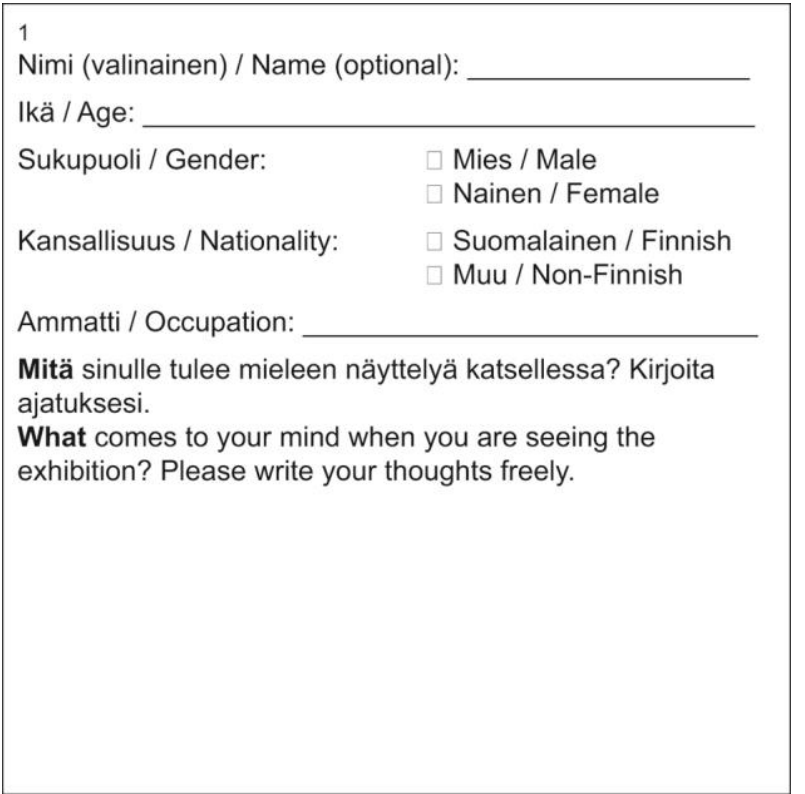

Figure 12: Questionnaire for Paper World (Nimkulrat, 2009, p. 72).

The output from the fourth phase, i.e., the Paper World series designed for a particular context, became the research problem and the input into knowledge production in the last phase. The positions of all the artworks in the gallery were intended to establish both the relationship between them and that between the artworks and the exhibition space. As can be seen in Figure 11, the proximities of some artworks to others were envisaged so that imaginative dialogues would be created between them. Questioning, in the form of printed questionnaires, was used to collect feedback from visitors during the Paper World exhibition. The results of the questionnaire in the third phase showed that some people used the same word or phrase for several of the artworks on their feedback forms. Asking visitors to give one word for an individual artwork thus seemed too demanding. The questions and the feedback form were therefore modified for the second exhibition, to give the visitors more freedom to write about their views (Figure 12). The small feedback forms documented how some visitors experienced and interpreted the artworks and the exhibition. I then scrutinized the visitors' experiences as reflected in their written feedback. Heidegger (1962) portrays the structure of experiences in the following way: people know how they will construe things before they really see them, by associating what they are experiencing with other, similar, things that they have experienced before (p. 191). The specific exhibition context affected most visitors' experiences and interpretations of the artworks and exhibition. As they were familiar with the forms of the everyday artifacts and with the homely exhibition space, and knew that a gallery is a place for displaying art, they understood that those forms of household artifacts made of paper string were not functional objects, but representational artworks. They experienced and interpreted the artworks and the exhibition as a whole in a way that was close to the concept I had conceived.

\section{Artifacts in combination with texts as inputs into knowledge and creative production and as outputs for knowledge communication}

With the interaction between different research approaches, i.e., literature review or questioning the audience interacting with making artifacts, Cases 1 and 2 (Seeing Paper and Paper World) could lead the process of inquiry. Thorough documentation of both art productions and the whole research process provided visual and textual data for analysis 
(Figure 5), generating the concept of "materialness" as the main research finding. This concept emphasizes the capability of a particular material to express meaning to the artist and viewers through its visual and tactile qualities. It is these physical qualities that influence the ways in which people comprehend artworks (Nimkulrat, 2009, pp. 208-209).

Whilst leading the process of inquiry, both the art productions and the artifacts produced functioned as "inputs into knowledge production" (Figure 13). This function can be recognized in the second phase of research in which the production of Case 1 attempted to uncover the expressive qualities of three different types of paper string. The metaphor for female humans expressed the idea that although the forms and structures were the same, the temperament and personality of each individual were inimitable due to each material's unique quality. Material was the major factor influencing both the emergence of the artworks and the artist's interpretations of the ongoing artworks in the creative process. As Dewey (1934) states, the artist's experience and action in controlling visual elements and the medium developed from his or her imagination, establish the expressiveness of an artwork or embody a meaning in it (pp. 89-91). The hand responds to the image and the idea the artist intends to express through manipulating the physical material, and the material in return sends the information about its qualities to the mind (Sennett, 2008, p. 149). The knowledge of material expressivity was thus attained because of the creation of artworks in Case 1 and through the resulting explicit articulation and reflective practice. Reflective practice itself is not knowledge, but rather a form of practice that supports the experiential knowledge tacitly constructed in the practice with moving from tacit to explicit. Reflection, as defined by Dewey (1933), is a rational and purposeful act that entails "active, persistent, and careful consideration of any belief or supposed form of knowledge in the light of the grounds that support it and the further conclusions to which it tends constitutes reflective thought" (pp. 119). Friedman (2003) highlights that although knowledge can be produced in part from practice, what establishes research is not practice but systematic and methodical inquiry into practice.

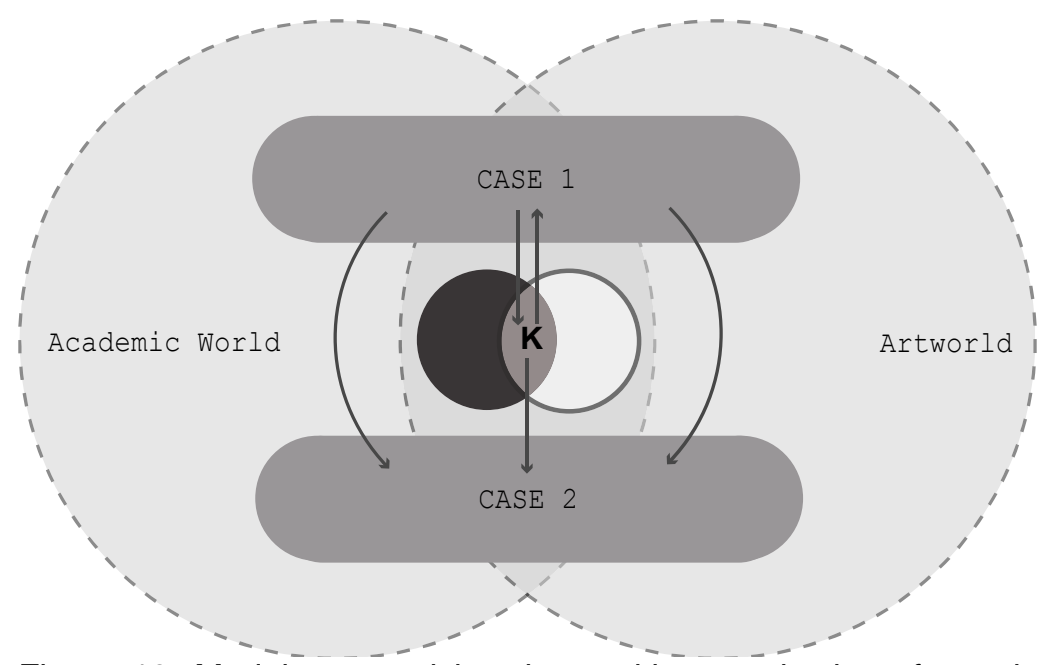

Figure 13: Model summarizing the positions and roles of creative artifacts in knowledge production and communication as well as in creative production. " $K$ " in the model stands for "knowledge." Case 1 (Seeing Paper) and Case 2 (Paper World) are situated in the research problem area as: 1) inputs into knowledge production, 2) outputs for knowledge communication, and 3) inputs into creation production.

When providing material for discussion and analysis, both the art productions and the artifacts produced performed as "outputs for knowledge communication" (Figure 13). This role can be seen in the final phase of research, not only in the exhibition of Case 2, but also in the written 
thesis. The exhibition in which all the exhibits were in the forms of functional objects situated in a contextualized space, demonstrated the material's expressivity over the form, serving as symbols of non-functionality and designating that the forms of useful objects cannot be used. In order to understand the meaning of an artwork, viewers cannot superficially look at the artwork but have to recognize and comprehend it (Risatti, 2007, p. 9). Phenomenological thinking (Heidegger, 1962; 1999; Merleau-Ponty, 1962) transformed the creation of Case 2. The exhibition as a whole, including the way in which artifacts were created in relation to the exhibition space, was the start of the creation and the meaning making process. The physical qualities of a material then manifested the intended meaning of artifacts that were constructed by that material within a specific exhibition context. An artifact becomes the embodiment of its maker's expressive thought. The actions of making embed meaning into the material artwork, which in turn defines and conveys its meaning through its physicality. The artwork (i.e., form and content), the context (i.e., space and time), and the people (i.e., artist and audience) are crucial elements involved in the research process and contribute to the output of research that is the concept of "materialness," or specifically, the expressivity of paper string, i.e., "paperness" (Nimkulrat, 2009). "Paperness" is not communicated solely through the artifacts produced in the researcher's process of inquiry, but in the written thesis in the form of a published book in which photographs of the ongoing and completed artifacts are included. The written text is a form of explicit articulation that allows a practitioner-researcher to compare and contrast theories acquired to examine his or her practice and to reflect on theories developed from the practice. Artifacts and their processes, when visually documented, can facilitate and support the articulation of knowledge to other people. Biggs (2002) stresses that the combination of artifacts and texts can be effective in knowledge communication, as follows:

Neither artefacts [sic] alone nor words/texts alone would be sufficient. What is required is the combination of artefact [sic] [painting, design, poem, dance, etc.] and a critical exegesis that describes how it advances knowledge, understanding and insight (p. 24).

Artifacts displayed in an exhibition can also simultaneously serve as "outputs for knowledge communication" and "inputs into knowledge production" (Figure 13). As can be seen in the third phase of research when Case 1 was publicly displayed in a modernist gallery, all artifacts in this series became the outputs of this phase of research, contributing to the knowledge of a material's expressivity through its physical qualities that affected not only the hand of the artist but also her expression. When the means of questioning the exhibition visitors was utilized, the exhibition and artworks functioned as a test space, developing into inputs for knowledge production. These inputs, when discussed with some theoretical foundations (e.g., O'Doherty, 1999; Dewey, 1934), contributed to the development of the research problem which grounded the fourth phase of research.

Moreover, artifacts can perform as "inputs into creative production" (Figure 13). This role can be seen in Case 1, when the viewers' feedback revealed that they did not recognize the difference in materials of the dress-like artifacts displayed in the modernist gallery and did not interpret the artifacts as a metaphor for human beings. This led not only to the subsequent research practice, but also the artistic one. Case 1 inspired the creative production of Case 2, the outcomes of which included research-informed artifacts that could be situated in both the academic and art contexts.

\section{Conclusion}

Throughout this article, I have attempted to identify the position of creative artifacts in research and their roles in the production and communication of knowledge of, and/or insight 
into, textile art practice from within the practice itself. This article has demonstrated the way in which practice may precede theory in practice-led research in art and design, and how practice may constitute new or enhanced theories that can then be adopted to develop the practice in return. Biggs's concept of knowledge in the art and design context (2004) indicates two kinds of knowledge: cognitive knowledge (or "knowing-that") and experiential knowledge (or "knowing-how"), both possibly occurring in different modes, such as explicit, implicit, or ineffable (p. 12). Creative artifacts with non-linguistic (ineffable or tacit) content are necessary for practice-based research only if they have a role in both the process and communication that can establish the ineffable content of knowing-that (p. 19). In other words, artifacts can support the understanding of knowing-that when it cannot be fully articulated. As shown in this article, knowledge creation about the expressivity of material in textile art was carried out within and through my practice. The results of the practice performed within the research context included not only creative artifacts with ineffable content situated in both academia and the artworld, but also explicit verbal reflection on the creative processes and the artifacts. By conducting practice-led research with thorough documentation, knowledge embedded in creative practice can no longer be completely tacit, but is explicit and shareable. In contrast, creative artifacts alone with no textual explanation will not be able to make the knowledge of the creation shareable. Creative practice in this form should not be credited for academic research.

The two cases presented in this article exemplify the roles of creative productions and artifacts situated in the process of inquiry. Throughout a practice-led research process, art and design artifacts can serve as inputs into knowledge production and as outputs for knowledge communication. As inputs, art productions and artifacts can:

- be the starting point of a research project from which the research questions are formulated;

- inspire a new creative production; and

- provide data for analysis from which knowledge is constructed.

As outputs, art productions and artifacts can:

- indicate whether the research problem requires reformulation;

- demonstrate the procedural or experiential knowledge of the creative process; and more importantly,

- strengthen findings articulated in the written output.

In an exhibition, artifacts function simultaneously as outputs for knowledge communication and as inputs into knowledge production when audiences' responses to the exhibits are systematically recorded and analyzed by the researcher. Moreover, in an exhibition open to the public, artistic processes and artifacts produced in academia can be recognized as "art proper" in the artworld as they can also reach a non-academic audience.

Creative practice in a research context can contribute to generating or enhancing knowledge which is embedded in the practice and embodied by the practitioner. This knowledge can be obtained from the artist creating the artifact, the artifact created, the process of making it, and the culture in which it is produced and viewed or used, all taking place at different stages of a research process.

The models utilized throughout this article can be considered theories. According to Friedman (2003), "a theory is a model" in the most basic form that illustrates "how something works by showing its elements in relation to one another" (p. 513). Artists and designers 
possess practical and experiential knowledge that may be shared with others. Once knowledge generated from within practice is disseminated, it is thereby validated as knowledge in an academic sense. Therefore, Figure 13 can be understood as a theory that describes the positions and roles of creative artifacts in art and design research and their contribution to bridging the academic world and the artworld.

\section{Nithikul Nimkulrat}

Lecturer in Textiles, Doctor of Arts

Loughborough University, School of the Arts

Email address: N.Nimkulrat@lboro.ac.uk or nithikul@inicreation.com

\section{References}

Biggs, M. (2002). The role of the artefact in art and design research. International Journal of Design Sciences and Technology, 10(2), 19-24.

Biggs, M. (2004). Learning from Experience: approach to the experiential component of practice-based research. In H. Karlsson (Ed.), Forskning, Reflektion, Utveckling [Research, Reflection, Development] (pp. 621). Stockholm: Vetenskapsrådet.

Biggs, M. (2006). Modelling Experiential Knowledge for Research. In M. Mäkelä \& S. Routarinne (Eds.), The Art of Research: Research Practices in Art and Design (pp. 182-202). Helsinki: University of Art and Design Helsinki.

Biggs, M. \& Karlsson, E. (2011). Evaluating Quality in Artistic Research. In M. Biggs \& E. Karlsson (Eds.), The Routledge Companion to Research in the Arts (pp. 405-424). London: Routledge.

Dewey, J. (1933). How We Think. Lexington, MA: D.C. Heath.

Dewey, J. (1934). Art as Experience. New York: Perigee.

Durling, D. (2002). Discourses on research and the PhD in Design. Quality Assurance in Education, 10(2), 7985 .

Frayling, C. (1993). Research in Art and Design. Royal College of Art Research Papers, 1(1), 1-5.

Friedman, K. (2003). Theory Construction in Design Research: Criteria: Approaches, and Methods. Design Studies, 24(6), 507-522.

Heidegger, M. (1962). Being and Time (J. Macquarrie \& E. Robinson, Trans.). London: Blackwell. (Original work published 1927).

Heidegger, M. (1999). Ontology: The Hermeneutics of Facticity (J. van Buren, Trans.). Bloomington, IN: Indiana University Press. (Original work published 1988).

Jarvis, P. (1999). The Practitioner-Researcher: Developing Theory from Practice. San Francisco, CA: JosseyBass.

Jarvis, P. (2012). Learning from Everyday Life. Human \& Social Studies. Research and Practice, 1(1), 1-20.

Kruskopf, E. (1975). Finnish Design 1875-1975: 100 Years of Finnish Industrial Design. Helsinki: Otava.

Lakoff, G. \& Johnson, M. (1980). Metaphors we live by. Chicago, IL: The University of Chicago Press.

Lycouris, C. (2011). Practice-Led Research in Arts, Design and Architecture. In T. Fell et al. (Eds.), Professional Doctorates in the UK 2011 (pp. 62-70). Lichfield: UK Council for Graduate Education.

Merleau-Ponty, M. (1962). Phenomenology of Perception (C. Smith, Trans.). London: Routledge. (Original work published 1945).

Niedderer, K. \& Roworth-Stokes, S. (2007). The Role and Use of Creative Practice in Research and its Contribution to Knowledge. Proceedings of IASDR International Conference 2007. Hong Kong: Hong Kong Polytechnic University. Retrieved August 31, 2013, from http://niedderer.org/IASDR07SRS.pdf.

Nimkulrat, N. (2009). Paperness: Expressive Material in Textile Art from an Artist's Viewpoint. Helsinki: University of Art and Design Helsinki. 
Nimkulrat, N. (2011). Problems of Practice-Based Doctorates in Art and Design: A Viewpoint from Finland. In C. Costley \& T. Fell (Eds.), $2^{\text {nd }}$ International Conference on Professional Doctorates (pp. 58-61). London and Lichfield: Middlesex University and UK Council for Graduate Education.

Nimkulrat, N. (2012). Voice of Material in Transforming Meaning of Artefacts. Proceeding of DRS Conference 2012. Bangkok: Chulalongkorn University.

O’Doherty, B. (1999). Inside the White Cube: The Ideology of the Gallery Space. Berkeley, CA: University of California Press.

Risatti, H. (2007). A Theory of Craft: Function and Aesthetic Expression. Chapel Hill, NC: University of North Carolina Press.

Scrivener, S. (2009). The Roles of Art and Design Process and Object in Research. In N. Nimkulrat \& T. O’Riley (Eds.), Reflections and Connections: On the Relationship between Creative Production and Academic Research (pp. 69-80). Helsinki: University of Art and Design Helsinki.

Schön, D. A. (1983). The Reflective Practitioner: How Professionals Think in Action. New York: Basic Books.

Schön, D. A. (1987). Educating the Reflective Practitioner: Toward a New Design for Teaching and Learning in the Professions. San Francisco, CA: Jossey-Bass.

Sennett, R. (2008). The Craftsman. New Haven, CT: Yale University Press.

Svinhufvud, L. (1998). Finnish Textiles en Route to Modernity. In M. Aav \& N. Stritzler-Levine (Eds.) Finnish Modern Design: Utopian Ideals and Everyday Realities, 1930-1997 (pp. 181-207). New York: Bard Graduate Center for Studies in the Decorative Arts. 